\title{
Population dynamics theory of plankton based on biomass spectra
}

\author{
Meng Zhou*, Mark E. Huntley \\ Marine Biology Research Division, Scripps Institution of Oceanography, University of California, San Diego, La Jolla, \\ California 92093-0202, USA
}

\begin{abstract}
Here we construct a fundamental mathematical theory of population dynamics in the context of the normalized spectra of abundance and biomass of plankton. The theory begins with the distribution function of abundance as a function of individual body weight and growth rate, and the law of the conservation of mass. The basic governing equations for population growth and biomass production are then deduced without empirical assumptions. The governing equations represent the fundamental mass balance between the biomass flux from small to large sizes due to individual growth and the sum of sources and sinks such as birth, natural death and predation. The slope of the normalized biomass spectrum at steady state is proved to be approximately equal to the ratio of the intrinsic rate of increase in abundance to individual weight-specific growth rate. We demonstrate that measurements of biomass spectra in nature can be used to estimate population-dynamics parameters of individual growth rate and the intrinsic rate of increase. We further apply this population dynamics theory to data collected by an Optical Plankton Counter in the California Current region during June and July, 1993. These data cover a range in the marine biomass spectrum from $10^{\circ}$ to $10^{4} \mu \mathrm{g} C$ individual body weight.
\end{abstract}

KEY WORDS: Population dynamics - Biomass spectrum - Mathematical theory $\cdot$ Marine plankton $\cdot$ Zooplankton - Individual growth rate Abundance. Productivity - Model · California Current

\section{INTRODUCTION}

Population dynamics theory based on analysis of species and stages cannot be applied practically to most natural communities of zooplankton. Models of population dynamics based on species and stages require separate determination of individual development, birth and mortality rates for each species and stage. The calculation of plankton biomass change due to both individual growth and population increase then requires the summation of rates from all species in the community. These rates can be determined either by using life-tables or by mathematical inverse-methods from field observations (e.g. Andrews 1966, Durbin \& Durbin 1981, Conover 1988, Ohman 1988, Carlotti \& Nival 1992, Huntley et al. 1994). Jørgensen (1990, 1994) reasoned that these approaches in which $10^{N-1}$ observations are required to determine the linear or nonlinear relations between $N$ components in an eco-

- Present address: Large Lakes Observatory, University of Minnesota, Duluth, MN 55812, USA.E-mail:mzhou@d.umn.edu system are impractical. For example, in a system of 3 species where each species has 3 stages, the relations between these 9 components require $10^{8}$ observations - a daunting task in any environment. Both simplification of population dynamics models and improvement of sampling technology are necessary to overcome the inconsistency between models and observations.

Biomass spectrum theory (Platt \& Denman 1977, 1978), an alternative perspective stemming from observations by Sheldon \& Parsons (1967) and Sheldon et al. $(1972,1977)$, classifies the plankton on the basis of size alone so that individual growth and population change could be estimated from allometrically-scaled rates. In early empirical work, most of the graphs of abundance versus size (individual biovolume) show similar trends, with a peak at the low end of the spectrum which quickly decreases to a relatively minuscule abundance for larger sizes (Sheldon et al. 1972, Rodríguez \& Mullin 1986, Sprules \& Munawar 1986). A comparison of 'normalized' biomass spectra (biomass normalized by weight interval) between inland lakes 
and open oceans was given by Sprules \& Munawar (1986). In inland lakes, the slope of normalized biomass spectra varied from -0.90 to -1.16 (Sprules \& Munawar 1986). In the north Pacific Central Gyre, the slope of normalized biomass spectra varied from -1.23 for microplankton to -1.13 for macrozooplankton, and from -1.32 at the surface to -1.13 at a depth of 100 to 120 m (Rodríguez \& Mullin 1986). The observed values appear to agree favorably with Platt \& Denman's (1978) theoretical value of -1.2 .

Parallel development of sampling technology in electronics and optics has provided an accurate means of 'sampling particles (Sheldon \& Parsons 1967, Herman 1988, 1992). Huntley et al. (1995) used such technology as the Optical Plankton Counter (OPC, Focal Instruments, Dartmouth, NS, Canada) to measure the mesoscale spatial distribution of zooplankton biomass and normalized biomass spectra in the California Current region. Heath (1995) used the same instrument, deployed on an ARIES system (Dunn et al. 1993) in Loch Linnhe, Scotland, to study the seasonal variation of zooplankton biomass.

The simplicity of measuring normalized biomass spectra has allowed empirical models to be concomitantly developed along with field observations. The most well-known empirical model was developed by Platt \& Denman $(1977,1978)$. A similar theory has also been developed for continuously structured populations in fishery and theoretical biology studies (VanSickle 1975, 1977, Aldenberg 1980). In Platt \& Denman's model $(1977,1978)$, which was generalized by Silvert \& Platt (1977), the flux of biomass produced mostly by individual growth within a weight interval, $\Delta w$, is equal to the respiration loss to the system at steady state. The respiration loss can be estimated from the product of individual respiration rate and the number of individuals within $\Delta w$. The slope of a biomass spectrum is equal to $-1+x-\alpha A$ at steady state, where $x, \alpha$ and $A$ are constants in allometric equations that define rates of respiration and individual growth.

By contrast, Heath (1995) indicated that the biomass of a group of individuals within a weight interval at a particular time is equal to the product of the individual weight and the number of individuals. Thus the change in biomass of this group is equal to the sum of individual growth and population increase, i.e., taking his notation, $N \mathrm{~d} w / \mathrm{d} t+w \mathrm{~d} N / \mathrm{d} t=w g N-w z N=$ $g(1-z / g)(w N)$, where $N$ is the number of individuals in a unit logarithmic interval of body weight (i.e. the normalized biomass spectrum), $w$ is the body weight, $g$ is the individual specific growth rate, and $z=$ $-(1 / N)(\mathrm{d} N / \mathrm{d} t)$ is the mortality rate. Based on the survivorship of a cohort described by Beyer (1989), the relationship between the normalized biomass spectrum and the individual weight can be expressed as
$N(w+\Delta w) / N(w)=[(w+\Delta w) / w]^{-z / g}$ which has a slope of $-z / g$. This solution of the biomass spectrum as a function of individual body weight differs from the solution of Platt \& Denman (1978). First, the energy balance is between growth and mortality, not between growth and respiration. Second, the slope is $-z / g$ instead of $-1+(x-\alpha A)$ where $(x-\alpha A)$ is the ratio of respiration rate to growth rate. Not only does the energy balance differ between these 2 models, but also the slopes of normalized biomass spectra in these 2 models differ by -1 . Furthermore, Heath's solution does not describe the change of biomass within a given weight interval.

Platt \& Denman's model provides a view, within a fixed weight interval, $\Delta w$, of the influx of biomass due to individual growth from relatively smaller individuals and of the outflux of biomass due to growth to relatively larger individuals. On the other hand, Heath's model provides a view of the increase in biomass, by following the same group of individuals, produced by both individual growth and population increase. Either approach is valid, but the solution of the biomass spectrum should be objective and unique. Thus Platt \& Denman's model and Heath's model should be mathematically unifiable, and should provide the same solution.

Another empirical assumption in the biomass spectrum theory is that there exists a unique growth rate for all species in each weight class. How will the variation of growth rate within a given weight class affect the mass balance in the model? We do not know how far this biomass spectrum model differs from reality. The biomass spectrum theory has suffered, like many models, from oversimplifications and unproved relationships. We therefore find it necessary to reformulate the theory without approximations, to solve the differences between models, and to provide examples of its application.

\section{DEVELOPMENT OF BASIC EQUATIONS}

Following Platt \& Denman $(1977,1978)$, we classify individuals in a plankton community at time $t$ in terms of body weight, $w$. The normalized biomass spectrum, $b(w, t)$, is defined as

$$
\left.b(w, t) \equiv \frac{\left.w H(w, t)\right|_{\left(w-\frac{1}{2} \Delta w, w+\frac{1}{2} \Delta w\right)}}{\Delta w} \text { (no. } \mathrm{m}^{-3}\right)
$$

where $\left.H(w, t)\right|_{\left(w-\frac{1}{2} \Delta w, w+\frac{1}{2} \Delta w\right)}$ is the histogram that is equal to the total number (no.) of individuals per unit volume within the weight interval $\left(w-\frac{1}{2} \Delta w, w+\frac{1}{2} \Delta w\right)$. The normalized abundance spectrum, $N(w, t)$, is defined as

$$
N(w, t) \equiv \frac{\left.H(w, t)\right|_{\left(w-\frac{1}{2} \Delta w, w+\frac{1}{2} \Delta w\right)} ^{\mid}}{\Delta w} \quad\left(\text { no }^{-3} \mu \mathrm{gC}^{-1}\right)
$$


In Platt \& Denman $(1977,1978)$, a practical way to obtain the normalized biomass spectrum was given by setting the weight interval of each weight category equal to the mean weight of that category, i.e. $\Delta w \approx w$. On the octave scale, we have

$$
\left.b(w, t) \approx H(w, t)\right|_{\left(w-\frac{1}{2} \Delta w, w+\frac{1}{2} \Delta w\right)} \text { when } \Delta w \approx w
$$

Thus, the normalized spectrum is equal to its histogram on the octave scale. Any spectrum not normalized by the weight interval is considered 'unnormalized'. Hence, for convenience of terminology, we assume that spectra are normalized unless otherwise stated, and refer to the 'normalized' spectra of Platt \& Denman $(1977,1978)$ simply as the biomass spectrum and the abundance spectrum. The relation between the biomass spectrum and the abundance spectrum is given by

$$
b(w, t)=N(w, t) w
$$

To develop the biomass spectrum theory, one growth rate was assigned to each weight class regardless of any difference between species and stages (Platt \& Denman 1977, 1978, Silvert \& Platt 1977). This approach does not take into account any variation in growth rate that may occur within a weight class, which in turn may affect results of the theory.

To account for variation in growth rate within a weight interval, individuals can be further classified by their growth rate, $G=\mathrm{d} w / \mathrm{d} t$. The number of individuals having their growth rate between $\left(G-\frac{1}{2} \Delta G\right.$,

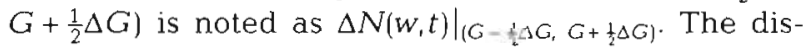
tribution function of abundance, $\dot{f}_{a}(w, G, t)$, is defined as

$$
f_{\mathrm{a}}(w, G, t) \equiv \frac{\left.\Delta N(W, t)\right|_{\left(C-\frac{1}{2} \Delta G, G+\frac{1}{2} \Delta G\right)}}{\Delta G}\left(\text { no. } \mathrm{s} \mathrm{m}^{-3} \mu \mathrm{gC}^{-2}\right)
$$

This distribution function represents zooplankton abundance in the interval $\Delta w, \Delta G$, i.e.

$$
f_{a}(w, G, t) \Delta G \Delta w \quad \text { (no. } \mathrm{m}^{-3} \text { ) }
$$

The abundance spectrum is then equal to

$$
\left.N(w, t)=\int_{0}^{\infty} f_{a}(w, G, t) \mathrm{d} G \quad \text { (no. } \mathrm{m}^{-3} \mu \mathrm{gC}^{-1}\right)
$$

The number of individuals per unit volume of water at time $t, N_{t}(t)$, i.e. plankton abundance, is equal to

$$
\left.N_{t}(t)=\int_{0}^{\infty} \int_{0}^{\infty} f_{a}(w, G, t) \mathrm{d} G \mathrm{~d} w \quad \text { (no. } \mathrm{m}^{-3}\right)
$$

We classify individuals in terms of both body weight and growth rate by the definitions given in Eqs. (2) \& (5). This is done exactly, i.e. without approximation. We can now construct a distribution function of abundance as a function of the body weight and growth rate.

Noting that at time $t+\Delta t$ this group of individuals has grown to a weight $w+\delta w$ and achieved a growth rate of $G+\delta G$, we have

$$
\begin{aligned}
& f_{a}(w+\delta w, G+\delta G, t+\Delta t) \Delta w \Delta G-f_{a}(w, G, t) \Delta w \Delta G \\
& \quad=\sigma \Delta w \Delta G \Delta t
\end{aligned}
$$

where $\delta w$ and $\delta G$ are the changes of weight and growth rate during $\Delta t$, and $\sigma$ is the rate of change (gain or loss) in abundance during $\Delta t$ within the interval $\Delta w \Delta G$. Letting $\Delta t, \Delta w, \Delta G \rightarrow 0$ in Eq. (9), we have

$$
\frac{\partial f_{a}}{\partial t}+\frac{\mathrm{d} w}{\mathrm{~d} t} \frac{\partial f_{a}}{\partial w}+\frac{\mathrm{d} G}{\mathrm{~d} t} \frac{\partial f_{a}}{\partial G}=\sigma
$$

which is in the form of Boltzmann's transport equation (DeGroot \& Mazur 1962). Integrating Eq. (10) in Gspace, we have

$$
\frac{\partial N}{\partial t}+\frac{\partial}{\partial w} \int_{0}^{\infty} G f_{a}(w, G, t) \mathrm{d} G+\int_{0}^{\infty} \frac{\mathrm{d} G}{\mathrm{~d} t} \frac{\partial f_{a}}{\partial G} \mathrm{~d} G=\int_{0}^{\infty} \sigma \mathrm{d} G
$$

The term on the right side of Eq. (11), also defined as $\mathrm{d} N / \mathrm{d} t$, represents the rate of change of abundance within the unit weight interval due to both birth and mortality. The time dependent growth rate, $\mathrm{d} G / \mathrm{d} t$, is determined by temperature, food, and body weight, which are not themselves functions of growth rate (Huntley \& Boyd 1984, Moloney \& Field 1989), i.e. $\mathrm{d} G / \mathrm{d} t \neq f(G)$. Thus, taking the conditions that $f_{a}(w, G=0, t)=f_{a}(w, G=\infty, t)=0$, the third term on the left of Eq. (11) becomes

$$
\begin{aligned}
\int_{0}^{\infty} \frac{\mathrm{d} G}{\mathrm{~d} t} \frac{\partial f_{a}}{\partial G} \mathrm{~d} G & =\frac{\mathrm{d} G}{\mathrm{~d} t} \int_{0}^{\infty} \frac{\partial f_{a}}{\partial G} \mathrm{~d} G \\
& =\frac{\mathrm{d} G}{\mathrm{~d} t}\left(\left.f_{a}\right|_{G=\infty}-\left.f_{a}\right|_{G=0}\right)=0
\end{aligned}
$$

Defining the mean growth rate $\bar{G}(w, t)$ at body weight $w$ as

$$
\bar{G}(w, t) \equiv \frac{1}{N(w, t)} \int_{0}^{\infty} G f_{a}(w, G, t) \mathrm{d} G
$$

This definition is a simple mathematical expression of the average growth rate at a given weight. This average growth rate can be calculated exactly from the growth rates of individuals, and is traditionally used in laboratory and field experiments. From this, the mean specific growth rate of a given weight is defined as

$$
g \equiv \bar{G} / w
$$

Eqs. (13) \& (14) are important to bridge our mathematical theory to the traditional definition of the mean growth rate obtained in laboratory and field observations.

Substituting Eqs. (12), (13) \& (14) into Eq. (11) and recalling the definition of $\mathrm{d} N / \mathrm{d} t$, we have the conservation equation of abundance, i.e.

$$
\frac{\partial N}{\partial t}+\frac{\partial(w g N)}{\partial w}=\frac{\mathrm{d} N}{\mathrm{~d} t}
$$

The second term on the left of Eq. (15) is the net flux of individuals through weight interval $\Delta w$ due to indi- 
vidual weight growth. Thus, $\partial N / \partial t$ is the total rate of change of abundance within the unit weight interval due to both the flux produced by individual growth $\partial(w g N) / \partial w$, and the change resulting from birth and mortality, $\mathrm{d} N / \mathrm{d} t . \mathrm{d} N / \mathrm{d} t$ can be interpreted as the rate of change in abundance of a selected group of individuals followed over time, $\Delta t$, and therefore can also be expressed as

$$
\frac{\mathrm{d} N(w, t)}{\mathrm{d} t} \equiv \mu(w, t) N(w, t)
$$

where $\mu$ is defined as the intrinsic rate of increase (e.g Fenchel 1974). Eqs. (15) \& (16) form the basic equations of conservation of individuals.

How can we determine $\mu$ ? For an enclosed community sorted by body weights, the change in population abundance, which results from the net effect of birth, natural death, and predation, can be exactly expressed as

$$
\begin{aligned}
& \frac{\mathrm{d} N}{\mathrm{~d} t}=\int_{0}^{\infty} r_{b}\left(w, w^{\prime}, t\right) N\left(w^{\prime}, t\right) \mathrm{d} w^{\prime} \\
& \text { Birth } \\
& -r_{d}(w, t) N(w, t)-\int_{0}^{\infty} r_{m}\left(w, w^{\prime}, t\right) N(w, t) N\left(w^{\prime}, t\right) \mathrm{d} w^{\prime} \\
& \text { Natural mortality } \quad \text { Predation mortality }
\end{aligned}
$$

where $r_{b}\left(w, w^{\prime}, t\right)$ is the per capita rate of increase in class $w$ due to reproduction derived from some other class, $w^{\prime}, r_{d}(w, t)$ is the per capita specific natural mortality rate, and $r_{m}\left(w, w^{\prime}, t\right)$ is the per capita predation rate on class $w$ by some other class, $w^{\prime}$. Thus, the first term represents the total rate of increase in class $w$ due to reproductive input from all classes, the second term is the natural mortality rate in class $w$, and the third term is the total predation mortality rate on class $w$.

However, Eq. (17) is still too complicated to be used in field applications, and it can be further simplified. From zooplankton data compiled by Huntley \& Lopez (1992, Table A1 therein), the approximate relation between the weights of adult parents and first-born juveniles is

Thus we have

$$
\log _{10}\left(\frac{w_{\text {parents }}}{w_{\text {juveniles }}}\right) \approx 2
$$

$$
w_{\text {juveniles }}=10^{-2} w_{\text {parents }}
$$

Given that the abundance spectrum is nearly a straight line with a slope of $-k$ (Sheldon et al. 1972, Rodríguez \& Mullin 1986, Sprules \& Munawar 1986, Sprules et al. 1988, Boudreau et al. 1991, Sprules et al. 1991, Boudreau \& Dickie 1992, Thiebaux \& Dickie 1992), we have

$$
\frac{N\left(w_{\text {parents }} t\right)}{N\left(w_{\text {juveniles }}, t\right)}=\left(\frac{w_{\text {parents }}}{w_{\text {juveniles }}}\right)^{-k}=10^{-2 k}
$$

This leads to the simplification that

$$
\begin{gathered}
\int_{0}^{\infty} r_{b}\left(w, w^{\prime}, t\right) N\left(w^{\prime}, t\right) d w^{\prime} \approx r_{b}\left(w, w_{\text {parents }} t\right) N\left(w_{\text {parents }}, t\right) \Delta W^{*} \\
\approx 10^{-2 k} r_{b}\left(w, w_{\text {parents }}, t\right) N(w, t) \Delta W^{\circ}
\end{gathered}
$$

where $\Delta w^{*}$ is the spectral width of weight intervals of the parents of individuals in the weight interval $\Delta w$. Thus we can simplify Eq. (17) as

$$
\begin{aligned}
\mu(w, t) & =10^{-2 k} r_{b}\left(w_{\text {parents }}, w, t\right) \Delta^{\prime} w \\
& -r_{d}(w, t)-\int_{0}^{\infty} r_{m}\left(w, w^{\prime}, t\right) N\left(w^{\prime}, t\right) \mathrm{d} w^{\prime}
\end{aligned}
$$

where $\mu(w, t)$ is the intrinsic rate of increase, or the specific population growth rate. Eq. (16) has been widely used (e.g. Fenchel 1974, Heath 1995). The expression (Eq. 22) shows that the intrinsic rate of increase could be a complicated functional of $N$. This discussion should not affect the generality of Eqs. (15) \& (16).

Now, substituting Eq. (16) into Eq. (15), we have

$$
\frac{\partial N(w, t)}{\partial t}+\frac{\partial[w g N(w, t)]}{\partial w}=\mu N(w, t)
$$

Multiplying Eq. (23) by $w$, we have the equation for the biomass spectrum, $b(w, t)$, as

$$
\frac{\partial b(w, t)}{\partial t}+\frac{\partial[w g b(w, t)]}{\partial w}=g b(w, t)+\mu b(w, t)
$$

On the left side of Eq. (24), the first term is the rate of change in biomass within unit weight interval $\Delta w$, and the second term is the net flux of biomass through weight interval $\Delta w$ due to individual growth. On the right side, the first term represents the change in biomass due to individual growth, and the second term represents the change in biomass due to change in population numbers. Now, if we follow through time interval $\Delta t$ the group of animals having weight $w$ at time $t$, the rate of change in their biomass, $\mathrm{d} b / \mathrm{d} t$, will be

$$
\frac{\mathrm{d} b}{\mathrm{~d} t}=\frac{\partial b}{\partial t}+\frac{\partial(w g b)}{\partial w}
$$

Eqs. (23) \& (24) require both initial and boundary conditions to define the existence and uniqueness of solutions. These are given by

$$
\begin{aligned}
& N(w, 0)=N_{0}(w) \\
& N(0, t)=0 \text { and } N(\infty, t)=0
\end{aligned}
$$

In practice, we can only measure individuals in some partial weight range $\left(w_{1}, w_{2}\right)$, which leads to the boundary conditions

$$
N\left(w_{1}, t\right)=N_{\mathrm{j}}(t)
$$

No boundary condition is required at weight class $w_{2}$ due to the hyperbolic characteristic of Eqs. (23) \& (24).

Integrating Eqs. (23) \& (24) and applying the boundary condition given in Eq. (27), we have the equations of total integrated abundance and biomass over all classes, i.e.

$$
\frac{\mathrm{d}}{\mathrm{d} t} \int_{0}^{\infty} N(w, t) \mathrm{d} w=\int_{0}^{\infty} \mu N(w, t) \mathrm{d} w
$$




$$
\frac{\mathrm{d}}{\mathrm{d} t} \int_{0}^{\infty} b(w, t) \mathrm{d} w=\int_{0}^{\infty} g b(w, t) \mathrm{d} w+\int_{0}^{\infty} \mu b(w, t) \mathrm{d} w
$$

These integration relations verify the conservation properties of Eqs. (23) \& (24). First, the intrinsic rate of increase determines the change in total abundance. Second, the individual growth rate and intrinsic rate of increase together determine the change of total biomass.

\section{CHARACTERISTICS OF SOLUTIONS}

\section{Steady state solutions}

At steady state, Eq. (23) can be written as

$$
\frac{\partial(w g N)}{\partial w}-\mu N=0
$$

The slope of $\log _{10}[N(w)]$ vs $\log _{10}(w)$ from this equation is equal to

$$
\frac{\partial \log _{10} N}{\partial \log _{10} W}=-\left(1+\frac{\partial \log _{10} g}{\partial \log _{10} W}\right)+\frac{\mu}{g}
$$

On the right side of Eq. (32), the first term represents the differential body growth $(\mathrm{wg})$, and the second term is the ratio of intrinsic rate of increase to individual weight-specific growth rate. The individual specific growth rate is a function of the body weight, e.g. $g=\left(h w^{n-1}-k w^{m-1}\right)$, where $h$ and $n$ are assimilation coefficients, and $k$ and $m$ are respiratory coefficients (Pütter 1920, von Bertalanffy 1938, Huntley \& Boyd 1984). The exponents, $n$ and $m$, are found to be approximately equal to $0.73-1.09$ (Mullin 1963, Mullin \& Brooks 1970, Ikeda 1977, Kato et al. 1982) and 0.7-1.0 (von Bertalanffy 1938, Zeuthen 1953, Ikeda 1970, Banse 1982), respectively. The slope of $\log _{10}(g)$ vs $\log _{10}(w)$ is determined by $n-1$ and $m-1$ which is of the order of $10^{-1}$. Neglecting this slope in Eq. (32), we have the slope of the abundance spectrum

$$
\frac{\partial \log _{10} N}{\partial \log _{10} w}=-1+\frac{\mu}{g}
$$

The steady state solution of abundance spectra above a certain weight, $w_{1}$, can be expressed as

$$
\frac{N(w)}{N\left(W_{1}\right)}=\left(\frac{W}{W_{1}}\right)^{s}
$$

Substituting Eq. (34) into Eq. (33), we obtain the equation for the slope of the abundance spectrum, $s$,

$$
s=-1+\frac{\mu}{g}
$$

Multiplying Eq. (34) by $\left(w / w_{1}\right)$ and incorporating Eq. (35), we can obtain the slope of the biomass spectrum, $s_{b}$,

$$
s_{b}=\frac{\mu}{g}
$$

The slope of the abundance spectrum is of the order -2 when the slope of the biomass spectrum is of the order -1 (e.g. Rodríguez \& Mullin 1986, Sprules \& Munawar 1986, Heath 1995). The sign of the biomass spectrum is directly determined by $\mu$, the intrinsic rate of increase, which is the rate of increase or decrease in population numbers. In most field observations, the slopes of biomass spectra are negative in the weight range of zooplankton $\left(10^{\circ}\right.$ to $10^{4} \mu \mathrm{g} \mathrm{C}$ ) (Sheldon et al. 1972, Rodríguez \& Mullin 1986, Sprules et al. 1988, Boudreau et al. 1991, Sprules et al. 1991, Huntley et al. 1995a). The intrinsic rate of increase, $\mu$, is negative.

At steady state, integrating Eq. (23) leads to

$$
\int_{0}^{\infty} \mu N(w) \mathrm{d} w=0
$$

If $\mu(w)$ above a certain weight is generally negative as discussed above, to obtain the balance suggested by Eq. (37), $\mu$ must be positive when the weight is lower than a critical weight, $w_{c}$. This implies that the total loss in number of plankton or biomass within the weight range larger than $w_{c}$ must be balanced by the import of plankton from the weight range less than $w_{c}$, i.e.

$$
\int_{0}^{w_{c}} \mu N(w) \mathrm{d} w=-\int_{w_{c}}^{\infty} \mu N(w) \mathrm{d} w
$$

Therefore Eqs. (35) \& (36) cannot be applied to weight classes smaller than $w_{c}$.

\section{Non-steady state solutions}

Eqs. (23) \& (24) are the general basic governing equations to describe the population dynamics. It is difficult to solve these equations analytically for a general non-steady state case. However, we can simplify these equations based on what we have learned regarding plankton processes in oceans, which allows us to learn some important characteristics of the nonsteady state solution. Note that the following simplifications are not necessary for field or modeling studies. These simplifications serve only to elucidate the fundamental biological processes involved in population dynamics.

From field observations of plankton in the weight range from $10^{\circ}$ to $10^{4} \mu \mathrm{g} \mathrm{C}$ (Sheldon et al. 1972, Rodríguez \& Mullin 1986, Sprules \& Munawar 1986), we have

$$
O[\partial \ln (b) / \partial \ln (w)]=10^{0}
$$

where $O(f)$ is a conventional mathematical symbol defined as the order of a variable quantity. 
In the discussion of the previous section, we have

$$
O[\partial \ln (g) / \partial \ln (w)]=10^{-1}
$$

Rearranging Eq. (24), we have the order of magnitude for each term,

$$
\begin{gathered}
\frac{1}{g} \frac{\partial \ln b}{\partial t}+\frac{\partial \ln b}{\partial \ln w}+\frac{\partial \ln g}{\partial \ln w}=\frac{\mu}{g} \\
10^{\circ}
\end{gathered}
$$

Thus, disregarding the third term on the left in Eq. (41) as negligible, the first order approximation of Eq. (41) is

$$
\frac{\partial \ln b}{\partial t}=\mu-g \frac{\partial \ln b}{\partial \ln w}
$$

Averaging this equation over a time period $T$, the term on the left of Eq. (42) vanishes, i.e.

$$
\frac{1}{T} \int_{0}^{T} \frac{\partial \ln b}{\partial t} \mathrm{~d} t=\frac{1}{T}\left[\left.\ln b\right|_{T}-\left.\ln b\right|_{0}\right] \stackrel{T \rightarrow \infty}{\longrightarrow} 0
$$

Then, we have

$$
\frac{\bar{\mu}}{\bar{g}}=\overline{\left(\frac{\partial \ln b}{\partial \ln w}\right)}+\frac{1}{\bar{g}} \overline{\left(g^{\prime} \frac{\partial \overline{\ln b^{\prime}}}{\partial \ln w}\right)}
$$

where $(\cdot)$ indicates a time average, and $b^{\prime}$ and $g^{\prime}$ represent temporal variations. We recognize that the variability of the biomass spectrum slope is of the order of $10^{-1}$ (Sheldon et al. 1972, Rodríguez \& Mullin 1986 , Sprules \& Munawar 1986, Huntley et al. 1995). Thus, the last term on the right of Eq. (44) must be small and negligible in the first order approximation. We conclude that the mean slope of the biomass spectrum is equal to the ratio of the mean intrinsic rate of increase to the individual weight-specific growth rate, i.e.

$$
\frac{\bar{\mu}}{\bar{g}}=\overline{\left(\frac{\partial \ln b}{\partial \ln w}\right)}
$$

This ratio is interesting because it actually provides a practical way to study rates of both individual growth and population increase from observations of biomass spectra.

Substituting Eq. (45) into Eq. (42), we obtain the tendency equation of the biomass spectrum

$$
\frac{\partial b}{\partial t}=b \bar{g}\left[\overline{\left(\frac{\partial \ln b}{\partial \ln w}\right)}-\frac{\partial \ln b}{\partial \ln w}\right]+b \bar{g}\left[\frac{\mu^{\prime}}{\bar{g}}-\frac{g^{\prime}}{\bar{g}} \frac{\partial \ln b}{\partial \ln w}\right]
$$

where $\mu^{\prime}$ represents the variation in $\mu$. The term on the left in Eq. (46) indicates the rate of change of the biomass spectrum. The first term on the right is the deviation of the slope from the mean. The second term represents the local fluctuations in rates of individual growth and population increase. The deviation of the slope always plays the role of restoring the slope to its mean, and the fluctuations of individual growth rate and the intrinsic rate of increase tend to drive the slope away from the mean.
Under an environmental condition, plankton adapt to a certain mean individual growth rate. This mean value should not be affected by mortality. The time scale of the first term on the right in Eq. (46) is determined by the individual specific growth rate, which is of the order of $10^{1}$ days $(1 / \bar{g})$ at $10^{\circ} \mathrm{C}$ (Huntley \& Lopez 1992). Mortality of plankton responding to starvation and predation pressure occurs in the order of hours to days, which is at least 1 order of magnitude less than the time scale of growth. Plankton may survive after a long period of starvation. Consequently, the time scale determined by the mean individual specific growth rate will also be significantly increased. To understand the effect of different time scales on Eq. (46), let us imagine what will happen after a steady state community is disturbed by starvation or the introduction of additional predators. In the first case, starvation will cause mortality to increase. When a certain percentage of plankton die of starvation, competition for food decreases and therefore mortality decreases. In the second case, mortality will increase due to additional predators, which causes a decrease in biomass. When biomass decreases to the point that limits predation, predators will move out of the plankton community to find other sources of food. In either case, the anomaly of mortality cannot last. The mortality will eventually decrease. Starvation may alter the individual growth rate temporarily. As starvation decreases, the individual growth rate should return to the normal mean value. After the disturbance, the disturbed biomass spectrum slope will recover to its mean slope in the time scale of $(1 / \bar{g})\left(>10^{1} \mathrm{~d}\right)$. Thus for short term disturbance, we have

$$
\frac{\partial b}{\partial t} \approx b \bar{g}\left[\frac{\mu^{\prime}}{\bar{g}}-\frac{g^{\prime}}{\bar{g}} \frac{\partial \ln b}{\partial \ln w}\right]
$$

In the time scale of more than $10^{1} \mathrm{~d}$, the disturbance of mortality can be neglected, so that Eq. (46) becomes

$$
\frac{\partial b}{\partial t}=b \bar{g}\left[\overline{\left(\frac{\partial \ln b}{\partial \ln w}\right)}-\frac{\partial \ln b}{\partial \ln w}\right]
$$

This equation can be used easily to estimate the rate of change in biomass or production for plankton in the weight range from $10^{\circ}$ to $10^{4} \mu \mathrm{g} \mathrm{C}$. Outside this weight range, we do not yet have enough observations to understand the characteristics of biomass spectra in order to make reasonable approximations.

\section{Applications to plankton population dynamics in the California Current region}

A large-scale survey of the upper ocean in the California Current was carried out during June and July 1993 and consisted of a series of onshore-offshore transects along longitude (Fig. 1; Huntley et al. 1995). An 


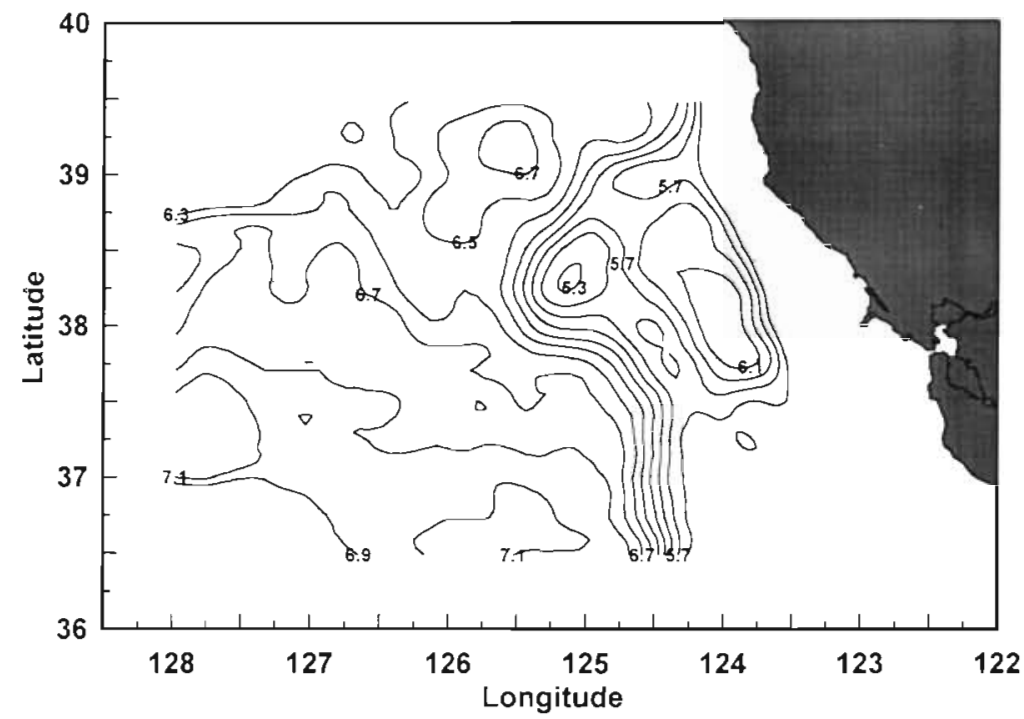

Fig. 1 Onshore-offshore cruise tracks and the dynamic height $(\mathrm{cm})$ at $25 \mathrm{~m}$ relative to $295 \mathrm{~m}$ from the large-scale survey of the California Current, June 6 to 28,1993

OPC mounted on a SeaSoar (Chelsea Instruments, East Molesey, Surrey, UK) was towed at a speed of 8 knots and undulated from the surface $(<5 \mathrm{~m})$ to almost $300 \mathrm{~m}$ at a period of approximately $8 \mathrm{~min} \mathrm{cycle}^{-1}(2 \mathrm{~km}$ cycle $\left.{ }^{-1}\right)$. To reduce sampling errors, the raw data were binned into $0.1^{\circ}$ in longitude, $10 \mathrm{~m}$ in depth, and 60 weight classes in equal increments of $230 \mu \mathrm{m}$ equivalent spherical diameter in the range between $270 \mu \mathrm{m}$ and $13.8 \mathrm{~mm}$. Then, the horizontal distribution of plankton biomass was calculated by integrating all OPC weight classes over the depth range 0 to $300 \mathrm{~m}$ (Fig. 2).

We selected 8 areas to study the biomass spectra where maxima or minima of plankton biomass were associated with eddies, meanders, and jets (Fig. 3). Each of these biomass spectra was averaged over the 0 to $300 \mathrm{~m}$ depth range within the red and yellow boxes shown in Fig. 2 . The biomass spectrum is noisy in large weight classes due to undersampling by the OPC To eliminate this noise, we used a leastsquares fit of a 4 th order polynomial function to the data.

It would be ideal if we had time series measurements of biomass spectra in our survey area which would allow us to compute the time averaged biomass spectrum slope directly in order to estimate the rate of

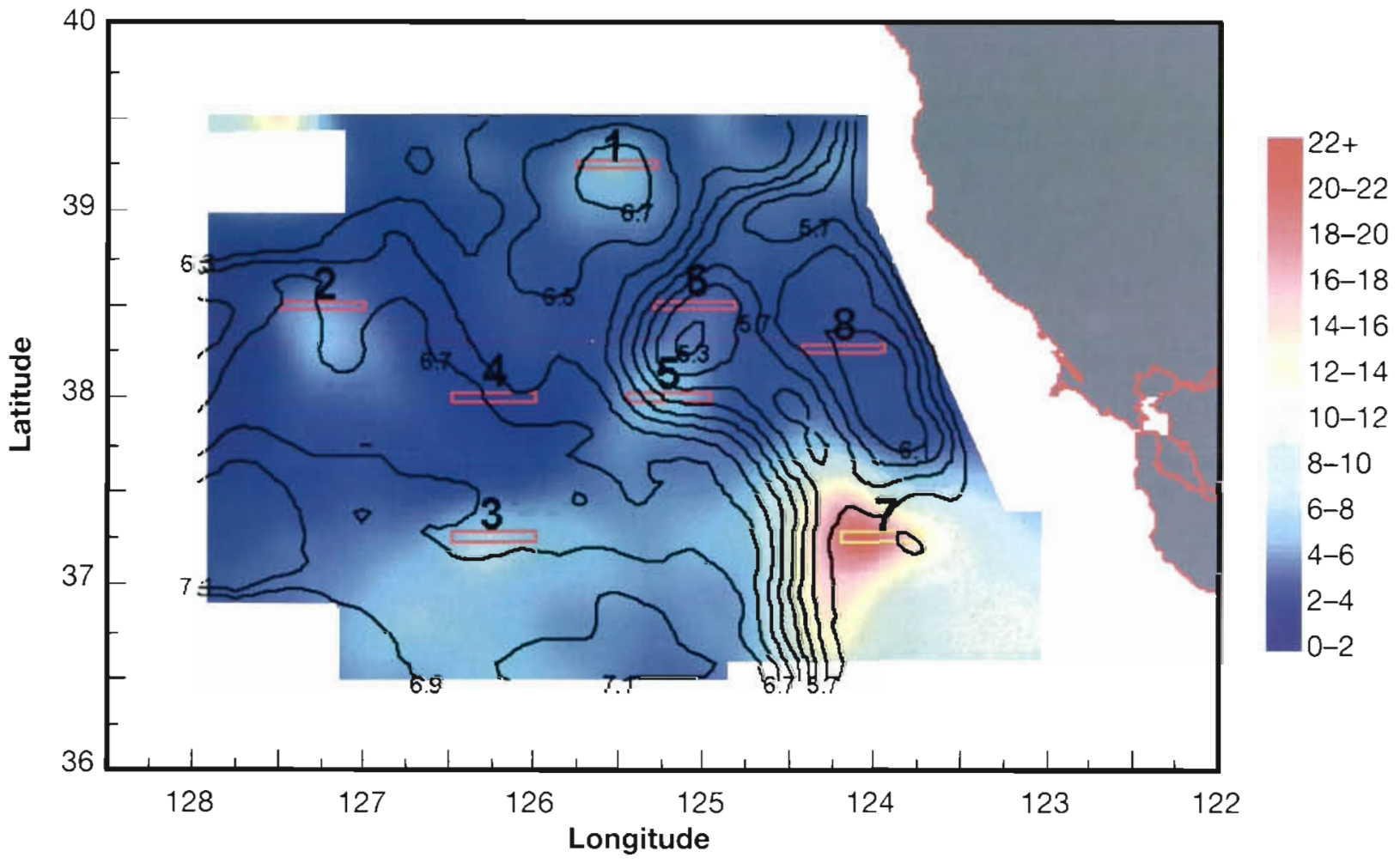

Fig. 2. Vertically integrated OPC measurements of total particle biomass $\left(\mathrm{g} \mathrm{C} \mathrm{m}^{-2}\right)$ in the upper $300 \mathrm{~m}$. Contours of dynamic topography are overlaid on false color contours of particle biomass. Numbered boxes indicate the selected areas for which the biomass spectra are shown in Fig. 3 


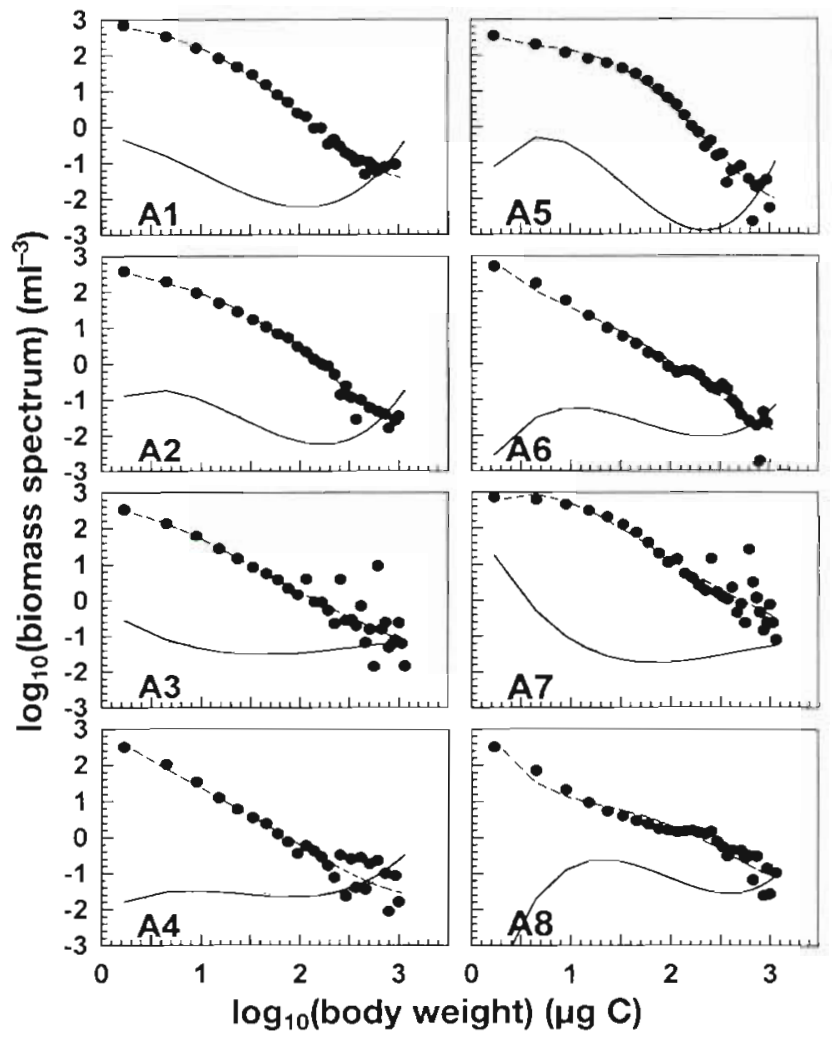

- Observed -...-Best-fit - - Slope Mean-slope

Fig. 3. Biomass spectra in the selected areas indicated in Fig. 2. The best-fit of the biomass spectrum is based on the least squares of the 4 th order polynomial function

change in biomass based on Eq. (45). However, this can be computed indirectly if the temporal average is substituted by the spatial average, which is true for the reasonable assumption that the process is Markovian (stationary process). We therefore first averaged the biomass spectrum from 0 to $300 \mathrm{~m}$ depth based on the data binned into $0.1^{\circ}$ in longitude, $10 \mathrm{~m}$ in depth, and 60 weight classes, and then calculated the slope of each biomass spectrum. The grand mean of those slopes throughout the entire survey area is referred to as the 'system slope'. Fig, 4 shows this system slope and its $95 \%$ confidence interval as the function of individual weight. The system slope of the biomass spectrum is approximately equal to -1.3 , which is similar to the slopes of $-1.34 \pm 0.21$ at the surface $(0$ to $20 \mathrm{~m})$, $-1.29 \pm 0.17$ at 40 to $80 \mathrm{~m}$ depth, and $-1.20 \pm 0.16$ at 100 to $120 \mathrm{~m}$ depth in the north Pacific Gyre during spring (Rodríguez \& Mullin 1986). The system slope shows relatively small variation in weight classes less than $10^{2} \mu \mathrm{g} \mathrm{C}$. The slope tends to increase to -0.6 at the weight of $10^{3} \mu \mathrm{g}$. Because large plankton were undersampled by the OPC due to its small intake cross-sectional area, the estimate of the slope at large weight classes is questionable.
The difference, within any weight class, between the system slope and a local biomass spectrum slope is interpreted as indicating a positive or negative change due to local processes of growth, birth and mortality.

\section{Areas 1 and 2 (offshore maxima)}

The northern maximum was located in an anticyclonic eddy (Area 1), and the central maximum was associated with the meandering of topographic height (Area 2). In the small weight range $\left(<10^{1} \mu \mathrm{g} \mathrm{C}\right)$, the negative difference between the system slope and the slope of the biomass spectrum indicates that the abundance of relatively smaller plankton was not enough to maintain the abundance of larger plankton due to differential growth rate $(w g)$, in which case the abundance should decrease. By contrast, in the larger weight classes $\left(>10^{1} \mu \mathrm{g} C\right)$, the slope of the biomass spectrum was higher than the system slope. The amount of smaller plankton exceeded the amount necessary to maintain the current amount of larger plankton. An increase in larger plankton would therefore be expected in the range $>10^{1} \mu \mathrm{g} C$. The overall biomass in all weight classes was decreasing.

\section{Area 3 (offshore maximum)}

This maximum was the second largest feature in our survey area, and was separated by the California Current jet from the coastal maximum. The slope of the biomass spectrum shows a weak departure from the system slope at all weights, which implies the biomass spectrum was nearly at steady state. To reach a steady state indicates the maturity of a plankton community in which both species and stages are in balance. The lack

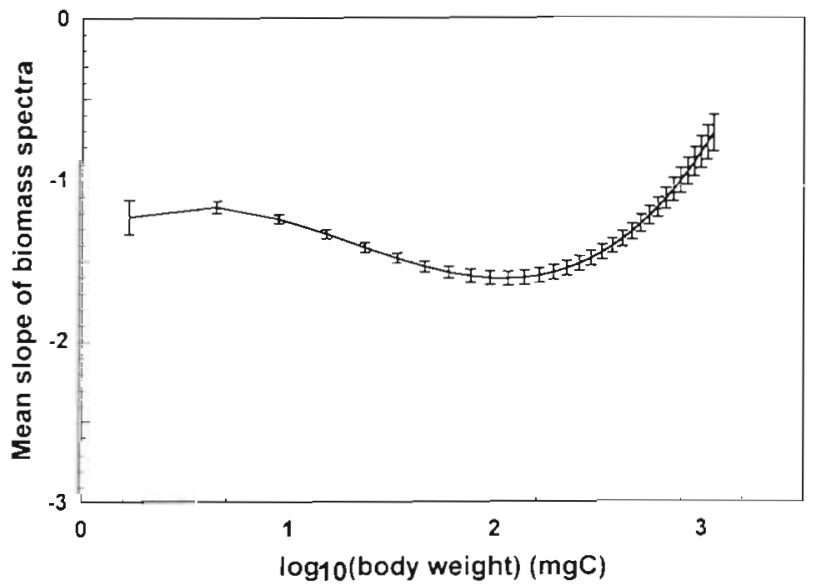

Fig. 4. Regional averaged slope of biomass spectra and $95 \%$ confidence interval 
of small weight particles causes a decrease in integrated biomass.

\section{Area 4 (offshore minimum)}

In this area, the relatively low biomass appeared to be at nearly steady state. Productivity was positive over most weight classes, and stable for large weight classes.

\section{Area 5 (maximum in the jet)}

This maximum was located in the center of the California Current next to a mesoscale eddy, and was characterized by a large amount of plankton in the weight range between 10 and $10^{2} \mu \mathrm{g} \mathrm{C}$. When this group of plankton grows into larger weight classes, an increase in biomass within those weight classes (>10 ${ }^{1.5} \mu \mathrm{g}$ C) would be expected. The small slope in weight classes $<10^{15} \mu \mathrm{g} C$ indicates that the biomass would decrease.

\section{Area 6 (maximum in the cyclonic eddy)}

In contrast to the maximum in the adjacent jet, there were 2 productive ranges on the biomass spectrum in this area: weight classes less than $10^{1} \mu \mathrm{g} C$ and those larger than $10^{1.6} \mu \mathrm{g} C$. This separation into 2 weight ranges may indicate the mixture of 2 groups of plankton: one group that had 'propagated' its biomass to classes $>10^{16} \mu \mathrm{g} \mathrm{C}$ due to individual growth and continued to propagate to larger weight classes; and another group $\left(<10^{1} \mu \mathrm{g} \mathrm{C}\right)$ which was 'newly' introduced into this biomass spectrum and was propagating towards the larger weight classes.

\section{Area 7 (coastal maximum)}

The highest biomass was found in this coastal region (Fig. 2), which contained high biomass over all weight classes. In large weight classes $\left(10^{1}\right.$ to $\left.10^{3} \mu \mathrm{g} \mathrm{C}\right)$, the biomass spectrum was nearly at steady state. However, because there were not enough small plankton $\left(<10^{1} \mu \mathrm{g} \mathrm{C}\right.$ ) to maintain the flux to the relatively larger weight classes, the biomass in this area could not be maintained. The decrease in biomass would propagate from small to large weight classes at the rate of individual growth

\section{Area 8 (coastal minimum)}

A minimum in biomass was found in the coastal anticyclonic eddy. The biomass spectrum shows a blooming or a pulse of small weight plankton $\left(10^{08} \mu \mathrm{g} \mathrm{C}\right)$. This pulse was distinguished from a flat 'old' biomass spectrum ( $>10^{1} \mu \mathrm{g} C$ ), in which the population was decaying. These small plankton would grow to large weight classes. Thus, this spectrum may show an early stage of plankton blooming in this coastal anticyclonic eddy.

\section{Horizontal distribution of production}

To obtain the horizontal distribution of plankton productivity, we integrate Eq. (48) over all OPC sizes to obtain the rate of change in plankton biomass, i.e.

$$
\frac{1}{B \bar{g}} \frac{\partial B}{\partial t}=\frac{1}{B} \int_{w_{1}}^{w_{2}} b\left[\overline{\left(\frac{\partial \ln b}{\partial \ln w}\right)}-\frac{\partial \ln b}{\partial \ln w}\right] d w
$$

where $B$ is the total biomass within the OPC weight range $\left(w_{1}=10^{\circ} \mu \mathrm{g} \mathrm{C}, w_{2}=10^{3} \mu \mathrm{g} C\right), B^{-1} \partial B / \partial t$ is the specific rate of change of biomass. Because $\bar{g}$ is not sensitive to the weight in the OPC size range as discussed above, the term on the right side of Eq. (49) represents the ratio of biomass specific rate of change of biomass to the individual mean growth rate within weight classes between $w_{1}$ and $w_{2}$. Fig. 5 shows the contour of this ratio in our survey area, which indicates regions where the change in biomass is positive or negative.

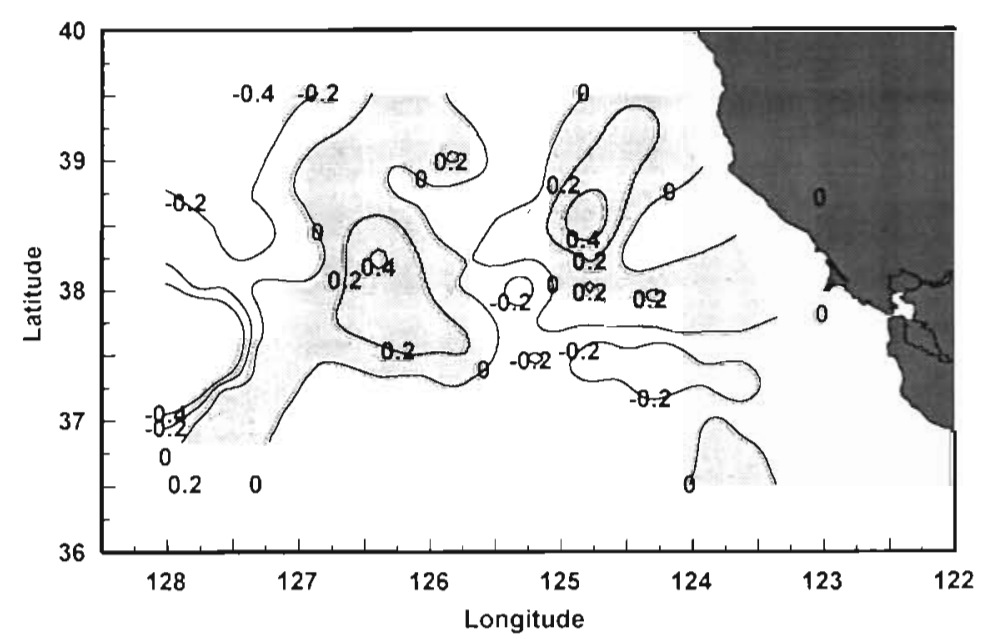

Fig. 5. The contours of $(\bar{g} B)^{-1} \mathrm{~d} B / \mathrm{d} t$, the nondimensional rate of change in biomass. The biomass in the shaded areas was increasing based on the prediction of Eq. (49) 


\section{DISCUSSION}

\section{Finite biomass}

Given the abundance spectrum expressed as Eq. (34) at steady state, we have the total biomass $\left(\mu \mathrm{g} \mathrm{C} \mathrm{m}^{-3}\right)$ above a given weight, $w_{1}$, by integrating the biomass spectrum, i.e.

$$
\int_{w_{1}}^{\infty} b(w) \mathrm{d} w=b\left(w_{1}\right) \int_{w_{1}}^{\infty}\left(\frac{w}{w_{1}}\right)^{s_{b}} \mathrm{~d} w \quad \begin{cases}=\text { finite } & \left(s_{b}<-1\right) \\ =\infty & \left(s_{b} \geq-1\right)\end{cases}
$$

This integration is finite when $s_{b}<-1$, or infinite when $s_{b} \geq-1$ Because the total mass must be finite, the slopes of biomass spectra must be less than -1 , which is the case for most observations (Sheldon et al. 1972, Rodríguez \& Mullin 1986, Sprules \& Munawar 1986) and also the case for the data presented in this article. That the system slope (Fig. 4) is larger than -1 for the

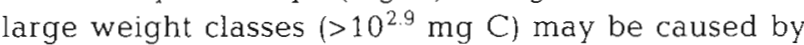
OPC undersampling. At steady state, the slope of the biomass spectrum is equal to $\mu / g$, so that the intrinsic rate of increase is always negative in the range where the slope is negative.

The conclusion that slopes of biomass spectra at steady state must be less than -1 can also be proved from the mass conservation. Integrating Eq. (24) over the weight range $\left(w_{1}, \infty\right)$, we have

$$
\frac{\partial}{\partial t} \int_{w_{1}}^{\infty} b d w=\left.w_{1} g b\right|_{w_{1}}+\int_{w_{1}}^{\infty}\left(1+\frac{\mu}{g}\right) g b d w
$$

The left side of $\mathrm{Eg}$. (51) is the rate of change in biomass within the weight classes $\left(w_{1}, \infty\right)$. On the right side, the first term is the flux from individuals smaller than $w_{1}$ due to growth, and the second term is the net production contributed by both individual growth and change in abundance in the weight classes $\left(w_{1}, \infty\right)$. At steady state

$$
0=\left.w_{1} g b\right|_{w_{1}}+\int_{w_{1}}^{\infty}\left(1+\frac{\mu}{g}\right) g b d w
$$

Because the first term on the right in Eq. (52), the flux into $\left(w_{1}, \infty\right)$, is generaliy positive, we must have $\mu / g<-1$ to keep this equation balanced.

Eq. (51) also indicates that the change in biomass contributed by individual growth and population increase is generally negative because $\mu / g<-1$. The increase in biomass in the range ( $w>10^{\circ} \mu \mathrm{g} \mathrm{C}$ ) is critically dependent on the flux term $\left.w_{1} g b\right|_{w_{1}}$. Thus, the study of population dynamics for those plankton within the classes $<10^{\circ} \mu \mathrm{g} C$ is very important.

In Platt \& Denman's model $(1977,1978)$, the estimate of the slope of a biomass spectrum requires the assumption that the turnover rate of biomass is equivalent to the turnover rate of numbers in a population.
This assumption has been made by a number of authors (e.g. Hall 1964, Heinle 1966, Walters 1977), but is fundamentally incorrect. Its fallacy has been demonstrated in detail (Rigler \& Downing 1984). However observations have shown that slopes of biomass spectra are approximately equal to -1 (Sheldon et al. 1972, Rodríguez \& Mullin 1986, Sprules \& Munawar 1986), so that, from Eq. (45), we conclude that at steady state the turnover rate of individual weight is not equal to, but is of the same order of the turnover rate of numbers in a population. The turnover rate of biomass of a population is equal to the sum of turnover rates of individual weight and numbers (Heath 1995).

\section{Spatial distribution of production and biomass}

Productive areas were located along the California Current, adjacent eddies, and an offshore region (shown in Fig. 5). The absolute rate of change in biomass requires the estimate of individual growth rate, which we do not know. Figs. $2 \& 5$ present a view of the biomass and relative rate of change of biomass at the moment we sampled. There is no positive correlation between the rate of change of biomass and biomass distribution. This implies that there must be some processes that decouple the correlation between the rate of change of biomass and biomass distribution.

Plankton in weight classes $10^{0}$ to $10^{4} \mu \mathrm{g} \mathrm{C}$ can be considered as passive particles because at the spatial scale of $10^{2} \mathrm{~km}$, the magnitude of current velocity is of the order of $10^{1} \mathrm{~cm} \mathrm{~s}^{-1}$, at least 1 order of magnitude higher than the swimming speed of zooplankton, which is approximately from $10^{-2}$ to $10^{0} \mathrm{~cm} \mathrm{~s}^{-1}$ based on compiled data from literature (Zhou \& Huntley 1996). The physical forcing by currents may play the most determinant role in the distribution of biomass Passive particles tend to flow to convergent areas, where water subducts, concentrations of nutrients are generally poor, and food for plankton is limited. In divergent flow areas, where upwelling and high concentrations of nutrients are usually found, passive particles tend to be advected and dispersed outwardly, so that the biomass of zooplankton is usually low even though the productivity is high.

\section{Field measurements and inverse methods to determine rates}

Though Eqs. (23) \& (24) describe the population dynamics from small to large weight classes, they do not form a closed set of equations. It is obvious that we must know the individual growth rate and the intrinsic 
rate of increase in order to solve these equations to fully describe population dynamics. We are also interested in variations of these rates on a time scale of $10^{\circ}$ to $10^{1} \mathrm{~d}$ and a spatial scale of $10^{1}$ to $10^{2} \mathrm{~km}$ due to special small- and mesoscale events. Any direct and indirect measurements of these rates based on current technology do not provide such resolution. We now demonstrate mathematically that Eqs. (23) \& (24) can be used as a practical method to estimate the individual weight-specific growth rate and intrinsic rate of increase from measured biomass spectra. These biomass spectra can be obtained by an OPC at both a high sampling speed and high resolution.

To show the procedure to estimate $\mu$ and $g$ without involving complicated mathematics, we will use Eq. (42), the simplified form of Eq. (23) or (24). The procedure itself can be applied to Eq. (23) or (24). Assuming that we have 2 measurements of $\partial \ln b / \partial t$ and $\partial \ln b / \partial \ln w$ at $t$ and $t+\Delta t$, we have from Eq. (42)

$$
\left\{\begin{array}{l}
\mu-\left(\left.\frac{\partial \ln b}{\partial \ln w}\right|_{t}\right) \times g=\left.\frac{\partial \ln b}{\partial t}\right|_{t} \\
\mu-\left(\left.\frac{\partial \ln b}{\partial \ln w}\right|_{t+\Delta t}\right) \times g=\left.\frac{\partial \ln b}{\partial t}\right|_{t+\Delta t}
\end{array}\right.
$$

Eq. (53) can be directly solved for $\mu$ and $g$.

To increase statistical significance, we can have sequentially sampled biomass spectra of the same population at times $\left(t_{1}, \ldots, t_{j}\right)$ at a time interval $\Delta t$, i.e

$$
\left\{b\left(w_{n}, t_{j}\right) i=1,2, \ldots, I, j=1,2, \ldots, J\right\}
$$

During the sampling period $\left(t_{1}, t_{j}\right)$, we assume these individual and population growth rates are nearly constant. At each weight class $w_{i}$, we replace the partial differential with the finite difference in Eq. (42) and rearrange, i.e.

$$
\begin{aligned}
& \left(\left.\ln b\right|_{1, j+1}-\left.\ln b\right|_{i, j}\right) \\
& +\frac{\Delta t}{\Delta \ln w} g_{i}\left(\left.\ln b\right|_{1, j}-\left.\ln b\right|_{i-1, j}\right)-\mu_{i} \Delta t=\varepsilon_{i j}
\end{aligned}
$$

where $\varepsilon_{i j}$ represents the residual error produced by the errors within measurements, $b\left(w_{i}, t_{j}\right)$. To reduce the standard errors of estimates by employing the leastsquares method, we define $\varepsilon^{2}$, the least squares error, which is the sum of the residuals of Eq. (55)

$$
\begin{aligned}
& \varepsilon^{2}= \\
& \sum_{i} \sum_{j}\left[\left(\left.\ln b\right|_{i, j+1}-\left.\ln b\right|_{i, j}\right)+\frac{\Delta t}{\Delta \ln w} g_{i}\left(\left.\ln b\right|_{l, j}-\left.\ln b\right|_{j-1, j}\right)-\mu_{i} \Delta t\right]^{2}
\end{aligned}
$$

The solutions of $g_{1}$ and $\mu_{j}$ at $w_{1}$ can be solved by minimizing the error, $\varepsilon^{2}$, i.e.

$$
\frac{\partial \varepsilon^{2}}{\partial g_{1}}=0, \quad \frac{\partial \varepsilon^{2}}{\partial \mu_{1}}=0 \quad i=1,2, \ldots, I
$$

The confidence level of the estimates can also be calculated from Eq. (56)

\section{Generality of the biomass spectrum model}

Here we have constructed a fundamental mathematical theory of population dynamics in the context of the abundance and biomass spectra of plankton (Eqs. 23 and 24). The theory begins with the distribution function of abundance as a function of individual body weight and growth rate, and the law of the conservation of mass. The basic governing equations for population growth and biomass production are then deduced without empirical assumptions. We have introduced a concept of the mean individual growth rate of a given class (Eq. 13). Employing the definition of mean individual growth rate allows us to avoid the simplification of assigning a unique individual growth rate to each weight class. This averaging method of individual growth rates is commonly used. No extra work and approximation are introduced by this definition. Eqs. (23) \& (24) are exact equations. The approximation of Eq. (17) is introduced for zooplankton (Eq. 22). This approximation should not affect the generality of Eqs. (23) \& (24)

The governing equations (Eqs. 23 and 24) represent the fundamental mass balance between the biomass flux from small to large sizes due to individual growth and the sum of sinks and sources such as birth and mortality. Thus, these equations can be used to predict the change of biomass within each weight class, which can be embedded easily into any ecosystem model.

Through the deduction of Eqs. (23) \& (24), we have also bridged the 2 models developed by Platt \& Denman (1977, 1978) and Heath (1995), so that in a fixed weight interval on the biomass spectrum, the rate of change in biomass and the flux of biomass due to differential individual growth are equal to the sum of individual growth and the rate of population increase (Eq. 24) instead of the respiration loss. The respiration loss of an individual is included in the energy budget of assimilation.

To close Eqs. (23) \& (24), the individual weight-specific growth rate and intrinsic rate of increase must be given as functions of species assemblage, food concentration and temperature. These functional relationships based on direct measurements are poorly quantified (Huntley 1988). We demonstrate that Eqs. (23) \& (24) can be used as a practical tool to estimate in situ individual weight-specific growth rate and intrinsic rate of increase based on biomass spectrum measurements. Sampling with plankton nets is needed to obtain the information regarding species assemblages in order to understand which species make the contribution to those rates. This analysis will in turn contribute to the study of rates based on species and stages. Thus, this combination of the analysis of biomass spectra, net sampling and other bio-physical 
measurements will lead us to predict the spatiotemporal distribution and productivity of marine plankton.

Acknowledgements. This research was supported by U.S. Office of Naval Research grant no. NOO014-92-J-1618, and U.S. National Science Foundation grant no. OCE-9711261 We acknowledge Yiwu Zhu for processing and analyzing OPC data. Special thanks are due to Mai D. G. Lopez, John R. Moisan and Tiffany K. Moisan for comments which improved this manuscript. This is contribution no. 14 of the Simon J Poole Institute of Theoretical and Observational Biology.

\section{LITERATURE CITED}

Aldenberg T (1986) Structured population models and methods of calculating secondary production. In: Metz JAJ, Diekmann $O$ (eds) The dynamics of physiologically structured populations. Lecture notes in biomathematics 68 . Springer-Verlag, Berlin, p 409-428

Andrews $\mathrm{KJH}$ (1966) The distribution and life-history of Calanoides acutus (Giesbrecht). Discovery Rep 34:117-162

Banse K (1982) Mass-scaled rates of respiration and instrinsic growth in very small invertebrates. Mar Ecol Prog Ser 9:281-297

Beyer J (1989) Recruitment stability and survival-simple size-specific theory with examples from the early life dynamics of marine fish. Dana 7:45-147

Boudreau PR, Dickie LM (1992) Biomass spectra of aquatic ecosystems in relation to fisheries yield. Can. J Fish Aquat Sci 49:1528-1538

Boudreau PR, Dickie LM, Kerr SR (1991) Body-size spectra of production and biomass as system-level indicators of ecological dynamics. J Theor Biol 152:329-339

Carlotti F, Nival P (1992) Model of copepod growth and development: moulting and mortality in relation to physiological processes during an individual moult cycle. Mar Ecol Prog Ser 84:219-233

Conover RJ (1988) Comparative life histories in the genera Calanus and Neocalanus in high latitudes of the northern hemisphere. Hydrobiologia 167/168:127-142

DeGroot SR, Mazur P (1962) Non-equilibrium thermodynamics. North-Holland Publishing Company, Amsterdam

Dunn J, Hall CD, Heath MR, Mitchell RB, Ritchie BJ (1993) ARIES - a system for concurrent physical, biological and chemical sampling at sea. Deep Sea Res 40:867-878

Durbin A, Durbin E (1981) Standing stock and estimated production of phytoplankton and zooplankton in Narragansett Bay, Rhode Island. Estuaries 4:24-41

Fenchel $\mathrm{T}$ (1974) Intrinsic rate of natura! increase: the relationship with body size. Oecologia 14:317-326

Hall DJ (1964) An experimental approach to the dynamics of a natural population of Daphnia galeata mendotal. Ecology 45:94-112

Heath MR (1995) Size spectrum dynamics and the planktonic ecosystem of Loch Linnhe. ICES J Mar Sci 52:627-642

Heinle DR (1966) Production of a calanoid copepod, Acartia tonsa, in the Patuxent River estuary. Chesapeake Sci 7: $59-74$

Herman AW (1988) Simultaneous measurement of zooplankton and light attenuance with a new optical plankton counter. Cont Shelf Res 8:205-221

Herman AW (1992) Design and calibration of a new optical plankton counter capable of sizing small zooplankton Deep Sea Res 39:395-415
Huntley ME (1988) Feedıng biology of Calanus: a new perspective. Hydrobiologia 167/168:83-99

Huntley M. Boyd C (1984) Food-limited growth of marne zooplankton. Am Nat 124:455-478

Huntley ME, Lopez MDG (1992) Temperature-dependent production of marine copepods: a global synthesis. Am Nat 140:201-242

Huntley ME, Zhou M, Lopez MDG (1994) Calanoides acutus in Gerlache Strait, Antarctica II. Solving an inverse problem in population dynamics. Deep Sea Res Il 41:209-227

Huntley ME, Zhou M, Nordhausen W (1995) Mesoscale distribution of zooplankton in the California Current in late spring, observed by Optical Plankton Counter. J Mar Res $53: 647-674$

Ikeda T (1970) Relationship between respiration and body size in marine plankton animals as a function of temperature. Bull Fac Fish Hokkaido Univ 21:91-112

Ikeda $T$ (1977) The effect of laboratory conditions on the extrapolation of experimental measurements to the ecology of marine zooplankton. IV. Changes in respiration and excretion rates of boreal zooplankton species maintained under fed and starved conditions. Mar Biol 41: 241-252

Jørgensen SE (1990) Ecosystem theory, ecological buffer capacity, uncertainty and complexity. Ecol Model 52:125-133

Jørgensen SE (1994) Fundamentals of ecological modeling. Elsevier, Amsterdam

Kato M, Segawa S, Tanoue E, Murano M (1982) Filtering and ingestion rates of the Antarctic krill Euphausia superba Dana. Trans Tokyo Univ Fish 5:167-175

Moloney CL, Field JG (1989) General allometric equations for rates of nutrient uptake, ingestion, and respiration in plankton organisms. Limnol Oceanogr 34:1290-1299

Mullin M (1963) Some factors affecting the feeding of marine copepods of the genus Calanus. Limnol Oceanogr 8: $239-250$

Mullin MM, Brooks ER (1970) Growth and metabolism of two planktonic, marine copepods as influenced by temperature and type of food. In: Steele JH (ed) Marine food chains. Oliver and Boyd, Edinburgh, p 74-95

Ohman MD (1988) Predator-limited population growth of the copepod Peseudocalanus sp. J Plankton Res 8:673-713

Platt T, Denman K (1977) Organisation in the pelagic ecosystem. Helgoländer Wiss Meeresunters 30:575-581

Platt T, Denman K (1978) The structure of pelagic marine ecosystems. Rapp Pv Réun Cons Int Explor Mer 173:60-65

Pütter A (1920) Studien über physiologische Ähnlichkeit. VI. Wachstumsähnlichkeiten. Pfluegers Arch Ges Physiol Menschen Tiere 1.80:298-317

Rigler FH, Downing JA (1984) The calculation of secondary productivity. In: Downing JA, Rigler FH (eds) A manual on methods for the assessment of secondary productivity in fresh waters. IBP Handbook \#17. Blackwell, Oxford, p $19-58$

Rodríguez J, Mullin MM (1986) Relation between biomass and body weight of plankton in a steady state oceanic ecosystem. Limnol Oceanogr 31:361-370

Sheldon RW, Parsons TR (1967) A continuous size spectrum for particulate matter in the sea. J Fish Res Bd Can 24: 909-91.5

Sheldon RW, Prakash A, Sutcliffe WHJ (1972) The size distribution of particles in the ocean. Limnol Oceanogr 17: $327-340$

Sheldon RW. Sutcliffe WH, Paranjape MA (1977) Structure of the pelagic food chain and the relationship between plankton and fish production. J Fish Res Bd Can 34: $2344-2353$ 
Silvert W. Platt T (1977) Energy flux in the pelagic ecosystem: a time-dependent equation. Limnol Oceanogr 23:813-816

Sprules WG, Brandt SB, Stewart DJ, Munawar M, Jin EH Love J (1991) Biomass size spectrum of the Lake Michigan pelagic food web. Can J Fish Aquat Sci 48:105-115

Sprules WG, Munawar M (1986) Plankton size spectra in relation to ecosystem productivity, size, and perturbation. Can J Fish Aquat Sci 43:1789-1794

Sprules WG, Munawar M, Jin EH (1988) Plankton community structure and size spectra in the Georgian Bay and North Channel ecosystems. Hydrobiologia 163:135-140

Thiebaux ML, Dickie LM (1992) Models of aquatic biomass size spectra and the common structure of their solutions. J Theor Biol 159:147-161

VanSickle $J$ (1975) The theory of physiological age distribu-

Editonal responsibility: Otto Kinne (Editor),

Oldendorf/Luhe, Germany tions in biological populations. PhD thesis, Michigan State University, East Lansing

VanSickle J (1977) Analysis of a distributed-parameter population model based on physiological age. J Theor Biol 64 : $571-586$

von Bertalanffy L (1938) A quantitative theory of organic growth (Inquiries on growth laws. 11). Human Biol 10: $181-213$

Waters TF (1977) Secondary production in inland waters. Adv Ecol Res 10:91-164

Zeuthen E (1953) Oxygen uptake as related to body size in organisms. Quart Rev Biol 28:1-12

Zhou M, Huntley ME (1996) The principle of biological attraction, demonstrated by the bio-continuum theory of zooplankton patch dynamics. J Mar Res 54:1017-1037

Submitted: January 17, 1997; Accepted: September 22, 1997 Proofs received from author(s): November 20, 1997 